\title{
On the consistency of model, ground-based, and satellite observations of tidal signatures: Initial results from the CAWSES tidal campaigns
}

\author{
W. E. Ward, ${ }^{1}$ J. Oberheide, ${ }^{2}$ L. P. Goncharenko, ${ }^{3}$ T. Nakamura, ${ }^{4}$ P. Hoffmann, ${ }^{5}$ \\ W. Singer, ${ }^{5}$ L. C. Chang, ${ }^{6}$ J. Du, ${ }^{7}$ D.-Y. Wang, ${ }^{1}$ P. Batista, ${ }^{8}$ B. Clemesha, ${ }^{8}$
} A. H. Manson, ${ }^{9}$ D. M. Riggin, ${ }^{10}$ C.-Y. She, ${ }^{11}$ T. Tsuda, ${ }^{12}$ and T. Yuan ${ }^{11}$

Received 3 June 2009; revised 16 October 2009; accepted 16 November 2009; published 14 April 2010.

[1] Comparisons between tidal wind signatures diagnosed from satellite and groundbased observations and a general circulations model for two (September-October 2005, March-April 2007) of the four Climate and Weather of the Sun-Earth System (CAWSES) Global Tidal Campaign observation periods are presented (CAWSES is an international program sponsored by Scientific Committee on Solar-Terrestrial Physics). Specific comparisons are made between model (extended Canadian Middle Atmosphere Model), satellite (Thermosphere Ionosphere Mesosphere Energetics and Dynamics (TIMED)), meteor, MF and incoherent scatter radar (ISR), and lidar tidal signatures in the mesosphere and lower thermosphere. The satellite and ground-based signatures are in good agreement and demonstrate for the first time that the tidal wind fields observed by both types of observations are consistent with each other. This is the first time that such agreement has been reported and effectively resolves the long-standing issue between ground-based radar and satellite optical measurements of winds. This level of agreement, which has proved elusive in the past, was accomplished by superposing the significant tidal components from the satellite analyses to reconstruct the fields observed by the ground stations. Particularly striking in these comparisons is the extent to which the superposed fields show strong geographic variability. This variability is also seen in the component superpositions generated from the extended Canadian Middle Atmosphere Model (eCMAM), although differences in the geographic patterns are evident.

Citation: Ward, W. E., et al. (2010), On the consistency of model, ground-based, and satellite observations of tidal signatures: Initial results from the CAWSES tidal campaigns, J. Geophys. Res., 115, D07107, doi:10.1029/2009JD012593.

\section{Introduction}

[2] Atmospheric tides are global-scale waves with frequencies that are harmonics of a day ${ }^{-1}$ which are primarily thermally driven by processes related to the solar heating of the atmosphere. The general theory describing their motion in a windless, constant temperature atmosphere was established close to 50 years ago [Chapman and Lindzen, 1970] and the modeling and theory needed to describe their creation and propagation in a realistic atmosphere developed close to 30 years ago [see Forbes, 1995, and references

\footnotetext{
${ }^{1}$ Department of Physics, University of New Brunswick, Fredericton, New Brunswick, Canada.

${ }^{2}$ Department of Physics, University of Wuppertal, Wuppertal, Germany.

${ }^{3}$ Haystack Observatory, MIT, Westford, Massachusetts, USA.

${ }^{4}$ National Institute of Polar Research, Tachikawa, Japan.

${ }^{5}$ Leibniz Institute of Atmospheric Physics, University of Rostock, Kühlungsborn, Germany.

${ }^{6}$ Department of Aerospace Engineering Sciences, University of Colorado at Boulder, Boulder, Colorado, USA.

Copyright 2010 by the American Geophysical Union. 0148-0227/10/2009JD012593
}

therein]. Nevertheless, full correspondence between modeling, ground-based observations and satellite observations has been difficult to achieve.

[3] Until recently the investigation of tidal signatures has tended to proceed somewhat independently in these three areas with intercomparisons highlighting the differences as much as the similarities [see, e.g., Pancheva et al., 2002; Cierpik et al., 2003]. The comparisons presented in this paper show for the first time that the tidal signatures from ground-based and satellite observations are consistent with each other. It appears that many of the differences between these various sources of information on tides are now resolved

\footnotetext{
${ }^{7}$ Department of Applied Mathematics and Theoretical Physics, Cambridge University, Cambridge, UK.

${ }^{8}$ National Space Research Institute, Saõ José dos Campos, Brazil.

${ }^{9}$ Institute of Space and Atmospheric Studies, University of Saskatchewan, Saskatoon, Saskatchewan, Canada.

${ }^{10}$ Colorado Research Associates, NorthWest Research Associates, Boulder, Colorado, USA.

${ }^{11}$ Department of Physics, Colorado State University, Fort Collins, Colorado, USA.

${ }^{12}$ RISH, Kyoto University, Uji, Japan.
} 
and systematic investigations of the actual relationships between the sources of tides and their presence throughout the atmosphere can now proceed.

[4] Past difficulties in achieving a consistent specification of the tidal fields were a result of differences in what aspect of the tidal field was being examined and the complexity of the tidal field. The net tidal field is a superposition of a number of different components so there is significant geographical variation in the amplitudes and phases of tides of various periods. Ground-based observations provide the net field at the various tidal frequencies whereas modeling efforts and satellite observations typically provide frequency and wave number resolved signatures. Suitable comparisons require either the resolution of the ground-based observations into their wave number components using longitude chains of observatories or the reconstruction by summation over wave number of the net fields above any particular station. Earlier difficulties appear to have been the result of comparisons between ground-based observations (which provide observations of a superposition of tidal components) and satellite or model results which are resolved into components.

[5] Until recently, the tidal parameters associated with nonmigrating tides (tidal signatures whose spatial/temporal form are non-Sun-synchronous; Sun-synchronous tides are termed migrating tides) were not generally available from satellite or model analyses and their importance not recognized. Networks of ground-based stations have only recently been developed [Pancheva et al., 2002; Manson et al., 2004a; Murphy et al., 2006; Manson et al., 2009] and the associated spatial resolution is still sparse for most latitudes so tidal components are difficult to resolve. Satellite observations have provided amplitudes and phases of various components and evaluations of longitudinal variability [Talaat and Lieberman, 1999; Manson et al., 2002; Forbes et al., 2003; Manson et al., 2004b; Forbes and Wu, 2006; Forbes et al., 2008; Oberheide et al., 2006, 2007] but systematic reconstructions of the net fields and direct comparisons with ground-based observations were rare. Nonmigrating tidal signatures have been calculated using mechanistic models [Lieberman and Leovy, 1995; Hagan and Forbes, 2002]. Analyses of tidal signatures in general circulation models have been undertaken in the past [Zwiers and Hamilton, 1986; Jackson, 1994; McLandress, 1997; Miyahara and Miyoshi, 1997] but apart from work by Miyahara's group [see Miyahara et al., 1999, and references therein] nonmigrating components were not emphasized until more recently [Grieger et al., 2002; Du et al., 2007; Yuan et al., 2008].

[6] The Climate and Weather of the Sun-Earth System (CAWSES) Global Campaign on Tides (a project in Theme 3 of the CAWSES program) is organized around four observation campaigns (September-October 2005, March-April 2007, June-August 2007, December-January 2008) and provides the opportunity for intercomparisons between various observations and models related to these campaigns. In this paper, results are presented from the first two campaigns which show consistent features between models and observations and excellent agreement between various wind observations, both ground-based and satellite. The selection of results from these first two campaigns is chosen to provide a sufficient variety of observation types and latitudinal bands (for which different tidal components are dominant) to demonstrate this agreement. Since the agreement is dependent on the reconstruction approach used here and not on the particular components used, a seasonal variation in the agreement is not to be expected. Further analysis of these campaigns is continuing and will be reported in future papers.

[7] Included in this paper are model analyses from the extended Canadian Middle Atmosphere Model (CMAM) [Fomichev et al., 2002], winds from the TIMED satellite (TIDI [Killeen et al., 2006] and SABER [Mlynczak et al., 2007]), meteor, medium frequency and incoherent scatter radar observations (see Fukao [2007] for a recent review), and wind lidar observations [She et al., 2003]. Following this introduction, reconstructed satellite and model diurnal meridional wind distributions at $\sim 90 \mathrm{~km}$ are presented and used to explain the overall context for the measurements presented in sections 3 and 4 . This is followed by a comparison of measurements from three stations in the southern tropics and TIDI analyses which show consistency between the satellite and ground-based observations of the diurnal meridional winds. Comparisons between 60 day running means of equatorial radar observations and TIDI analyses of the diurnal zonal wind field follow which demonstrate consistency between these measurements. A comparison, at midlatitude sites, between incoherent scatter, MF radar, lidar, TIDI and model results for the zonal diurnal and semidiurnal wind amplitudes and phases showing good agreement follows. The paper concludes with a discussion of the implication of these measurements and future investigations.

[8] The results selected for presentation in this paper were chosen to demonstrate the breadth of agreement between various observation types and at different latitudes. The satellite results serve as the means to compare observations from different sites, since the reconstructions at a given time are all made from the same set of satellite derived components. Results from the southern tropics are included to show that amplitude modulation and phase variation with longitude between the satellite reconstructions and groundbased observations are in good agreement at latitudes where the migrating diurnal tide is the dominant component. The comparison between the satellite and equatorial radar is included to demonstrate that the agreement is also good for the case where the nonmigrating components are dominant. Finally the midlatitude comparison between the satellite and observations with several different types of instruments is included to demonstrate that this agreement extends across instrument types and is primarily due to the use of reconstructions.

[9] The model results show moderate agreement with the observations. They are included to demonstrate that while the general form of the geographical variability is simulated in a general circulation model, good agreement is unlikely without accurate duplication of source characteristics and atmospheric conditions. A substantial amount of work is required for models to achieve good agreement with observations.

\section{Model and Satellite Comparison}

[10] Figure 1 presents a latitude versus longitude cross section at $90 \mathrm{~km}$ of the net diurnal tidal meridional wind fields generated by superposing the diagnosed diurnal tidal components (wave numbers 0 to 5) for September 2005. Figure 1a shows the field constructed from 60 day running 

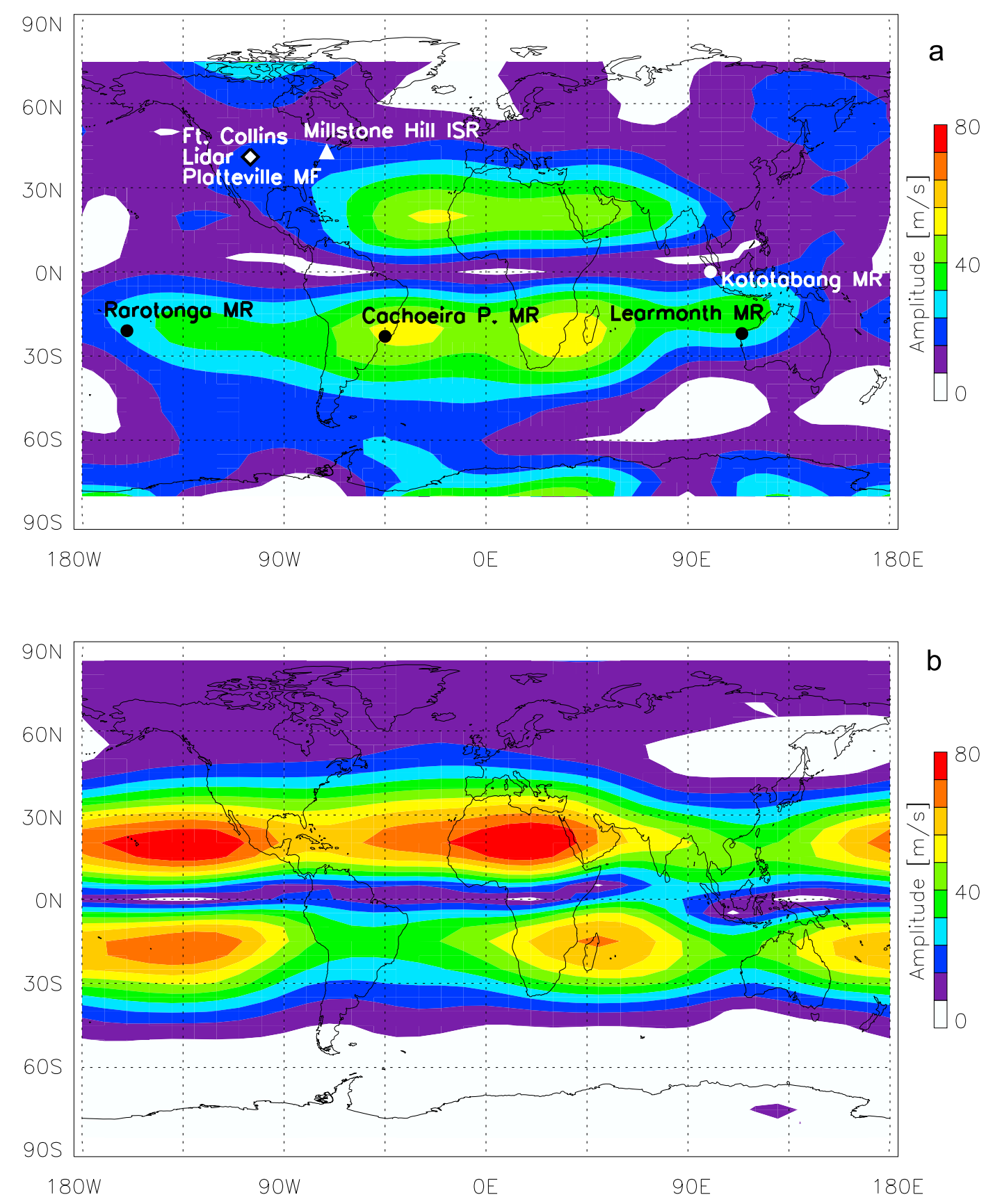

Figure 1. Latitude versus longitude cut of the net amplitude of the meridional wind $(90 \mathrm{~km}$, September 2005) of the diurnal tide reconstructed from the diurnal components diagnosed from (a) the TIDI observations and (b) the eCMAM. Results for the first campaign are shown.

mean TIDI observations of nonmigrating tides and migrating tidal winds derived from SABER (Version 1.06) tidal temperature observations using Hough Mode Extensions as exemplified by Oberheide and Forbes [2008]. For Figure 1a the running mean is centered in the middle of September. It is referred to as TIDI observations in the following. The time resolution for the TIDI results is limited to 60 days because of the precession rate of the TIMED satellite. Figure $1 \mathrm{~b}$ shows the results from a model run with the extended Canadian Middle Atmosphere model (eCMAM) [Fomichev et al., 2002]. The tidal components were diagnosed as described by Ward et al. [2005] and Du et al. [2007]. These reconstructions involve vector (phasor) summations at each latitude and longitude over the diagnosed wave number components taking into account the intrinsic phase of each component and the phase shift associated with the longitude. Interference effects between components result in significant variations in the net amplitude and phase as a function of longitude. Indicated in Figure 1a are the geographic locations of the ground-based observations discussed later in the paper. Throughout this paper, the satellite and model results are superpositions of this type. 
[11] Particularly striking in Figure 1 is the degree of longitudinal variability in the amplitude of the net diurnal field. If the migrating diurnal tide was the dominant component in the terrestrial atmosphere at mesospheric heights then a plot of the net field would be independent of longitude. The nonmigrating tides are significant enough to cause a strong modulation in longitude and in the satellite field at certain longitudes superpose in such a way as to cancel the migrating tide. Figure 1 illustrates why there has been so much variability in the tidal analyses from ground-based stations. At each latitude and height, the longitudinal phase dependence of each components varies in accordance with its wave number so that the phase superposition of the various diurnal components varies as a function of longitude In addition since the relative amplitudes vary with latitude and height, the component compositions at each latitude and height are different.

[12] Plots such as those in Figure 1 provide an alternative means to present tidal fields and emphasize the geographical variation in the amplitudes for the tidal frequency of interest. The model and satellite results differ in detail, although the general form of the superposition is similar. Comparisons between the model and satellite net fields for other months (not shown) show varying degrees of agreement, with April 2007 showing particularly good agreement in both the amplitudes and locations of the maxima and minima. However, it is clear that agreement between models and observations will be difficult since the model must correctly simulate the phases and amplitudes of the tidal forcing of the various components and the background zonal mean conditions that the tides propagate through. Because the model run used in this comparison did not correspond to the actual atmospheric conditions present during the observations, we consider agreement beyond general seasonal agreement in terms of latitudinal structure and general form of the longitudinal variations to be fortuitous. This also implies that model/observation comparisons must be made very carefully since observations at single stations provide information on superpositions between components. These are unlikely to correspond to the vertical structure associated with any individual component.

[13] A detailed analysis of the differences between the model and satellite analyses is beyond the scope of this paper. The differences are a function of the component strengths which vary with location, height and season and depend on the parameterizations used in the model (convective adjustment, latent heat release, gravity wave, etc.) and differences in the background fields and large-scale wave fields. Comparisons of this type will provide valuable information for the validation of models and will be a significant area of future research.

\section{Ground-Based Radar and Satellite Comparisons}

[14] Confirmation of the accuracy of these satellite analyses is provided through comparisons with ground-based observations of the meridional winds in the upper mesosphere/ lower thermosphere. Three ground-based meteor radars (Rarotonga $\left(21^{\circ} \mathrm{S}, 160^{\circ} \mathrm{W}\right)$, Cachoeira Paulista $\left(23^{\circ} \mathrm{S}, 45^{\circ} \mathrm{W}\right)$ and Learmonth $\left(22^{\circ} \mathrm{S}, 114^{\circ} \mathrm{E}\right)$; see Figure 1 for their locations) situated on the $20^{\circ} \mathrm{S}$ latitude circle took observations during the first campaign (September-October, 2005). Sixty day vector averages of their observations are shown in Figure 2 along with the associated reconstructed fields at the same locations from the TIMED satellite. The top (Vorrom) plots in Figure 2 show the amplitudes (phases) for these locations with the solid lines showing the data and the shaded regions the standard deviations.

[15] The satellite analyses provided in Figure 1 indicate that the tidal amplitudes at $90 \mathrm{~km}$ at the three stations should be $\sim 25 \mathrm{~m} / \mathrm{s}$ (Rarotonga), $\sim 50 \mathrm{~m} / \mathrm{s}$ (Cachoeira) and $\sim 32 \mathrm{~m} / \mathrm{s}$ (Learmonth). The ground-based observations are in agreement with these values within the experimental error. Moreover, the agreement extends throughout the profiles both in phase and amplitude. Good agreement of this caliber between satellite and ground-based observations has never been achieved prior to this analysis.

[16] In Figure 3, comparisons are shown between the net diurnal zonal wind field determined from TIMED observations and meteor radar observations at Kototobang $\left(0^{\circ} \mathrm{N}\right.$, $100^{\circ} \mathrm{E}$ ) during the second campaign (March-April 2007). Figures $3 \mathrm{a}, 3 \mathrm{~b}, 3 \mathrm{~d}$, and $3 \mathrm{e}$ show the 60 day running means (for amplitude in Figures $3 \mathrm{a}$ and $3 \mathrm{~b}$ and phase in Figures $3 \mathrm{~d}$ and $3 \mathrm{e}$; Figures $3 \mathrm{a}$ and $3 \mathrm{~d}$ are from TIMED, and Figures $3 \mathrm{~b}$ and $3 \mathrm{e}$ are from radar) as a function of day number, and Figures $3 \mathrm{c}$ and $3 \mathrm{f}$ show the campaign mean amplitudes and phases, respectively. The radar data were averaged over the same 60 day periods used to determine the TIMED observations and a particular day number represents the midpoint of the 60 day interval. Horizontal bars indicate standard deviations. The horizontal dashed lines in the plots are at the same heights in each plot and are included to facilitate comparison of the observations.

[17] In the campaign mean plots, the height variation of the amplitudes is similar but the meteor radar winds are larger. The difference is within the uncertainties of the measurements. The campaign mean phases agree very well except for a point at $82.5 \mathrm{~km}$, with both sets of observations showing slow decreases in phase with height. The running mean amplitude plots evolve in time in a similar manner. Both show the amplitude slowly decreasing with time in the 85 to $95 \mathrm{~km}$ region with a minimum in the height profile forming close to $88 \mathrm{~km}$ about day 100 . The time evolutions of the phases are also similar. The phase between 85 and $98 \mathrm{~km}$ increases slowly with time to around day 100 . At this point, the phases decrease in both observation sets in the height range of 85 to $90 \mathrm{~km}$. Above this height, the phase variation differs slightly between the two, with the phase continuing to increase in the TIDI observations whereas in the radar observations the phase decreases slightly. Again, the agreement is very good.

[18] These two examples illustrate agreement between the satellite reconstructions and the ground-based observations for two different situations and different time periods. The winds (zonal and meridional) associated with the migrating diurnal tide maximize in midlatitudes and minimize at the equator [McLandress, 1997]. Hence the midlatitude example corresponds to the case where the migrating diurnal tide dominates and the nonmigrating components modulate the longitudinal amplitudes and phases. In contrast, for the equatorial comparison, many components contribute without any one dominating (see Oberheide et al. [2006] for a summary of the amplitudes and phases of the nonmigrating 

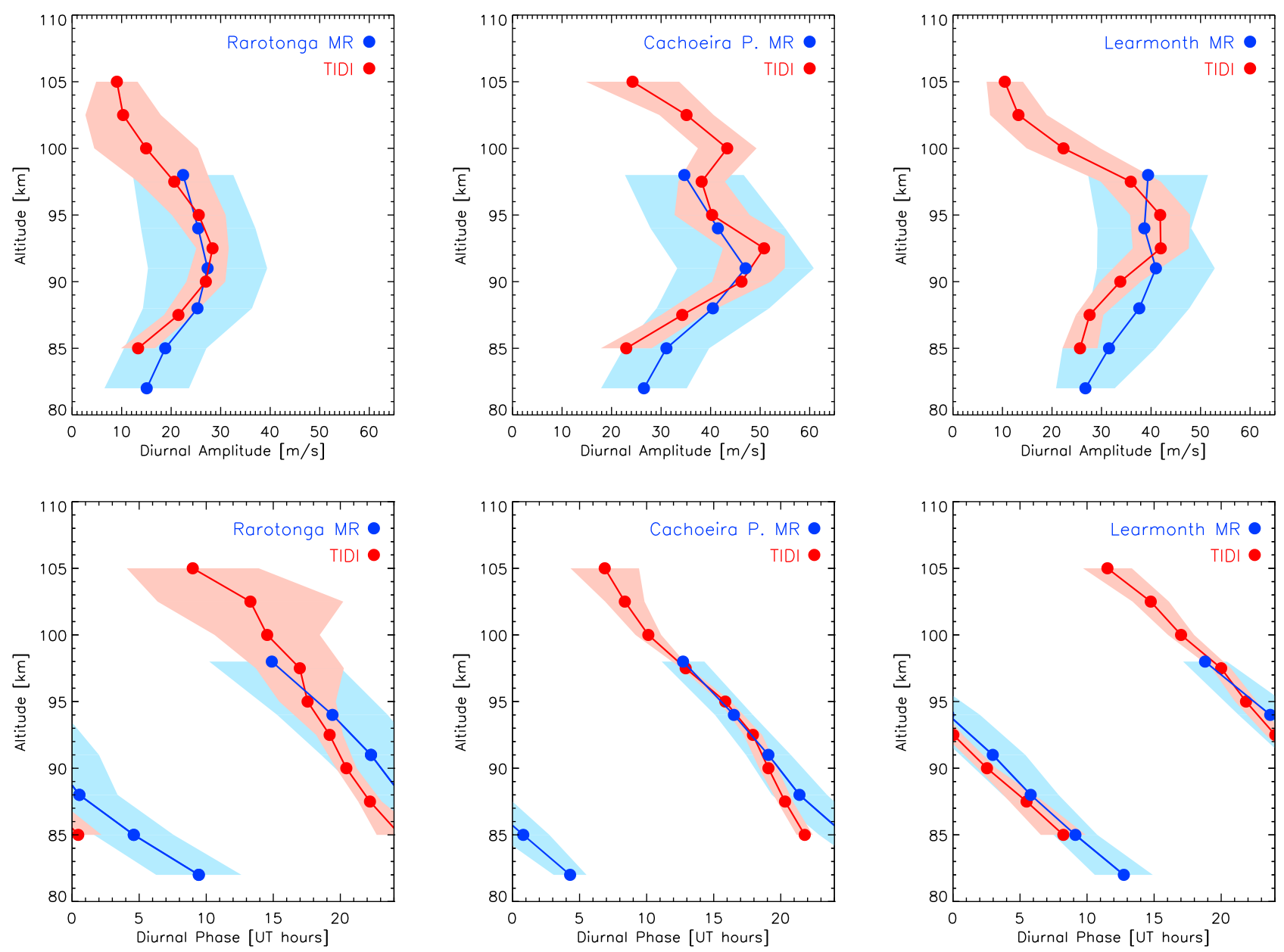

Figure 2. Height profiles (September-October 2005, first campaign) of the diurnal (top) amplitude and (bottom) phase (universal time of maximum) of the meridional wind for three stations and TIDI (60 day means) located at different longitudes near the $20^{\circ} \mathrm{S}$ latitude circle (see Figure 1 for the locations). Shading indicates standard deviation.

components). The agreement in both cases indicates that this consistency is not by chance.

[19] As can be seen in Figure 1, the model does not duplicate the longitudinal amplitude variation seen at midlatitudes with the radar and satellite reconstruction. The amplitude variation with longitude differs since the nonmigrating component mix does not correspond to what is observed.

\section{Incoherent Scatter Radar, Lidar, MF Radar, Model, and Satellite Comparison}

[20] Figure 4 shows comparisons of the diurnal and semidiurnal tidal signatures in the zonal wind for SeptemberOctober 2005 between three ground-based observations and the satellite (TIDI) and model (eCMAM) reconstructions for midlatitude locations near $40^{\circ} \mathrm{N}$ and $70^{\circ} \mathrm{W}$. This set of comparisons is selected to demonstrate agreement between several different types of observations. The agreement between the meridional wind fields is similar. The groundbased observations include lidar winds from Fort Collins $\left(41^{\circ} \mathrm{N}, 105^{\circ} \mathrm{W}\right)$, incoherent scatter radar winds from Millstone Hill $\left(42.6^{\circ} \mathrm{N}, 71.5^{\circ} \mathrm{W}\right)$ and $\mathrm{MF}$ radar winds from
Platteville $\left(40^{\circ} \mathrm{N}, 105^{\circ} \mathrm{W}\right)$. For these comparisons, the lidar and ISR results are generated from shorter data sets ( 9 days and 30 days, respectively) whereas the other data sets are longer-term averages (60 days). As a result, some of the shorter-term variability will be present in the former profiles.

[21] These sites differ somewhat in longitude but the reconstructed profiles for the two sites are quite similar. The satellite reconstruction for $105^{\circ} \mathrm{W}$ (Fort Collins, Plattville, not shown for clarity) indicates that relative to the Millstone Hill results, the zonal diurnal amplitude is in agreement from 80 to $90 \mathrm{~km}$, is less than Millstone Hill by $\sim 5 \mathrm{~ms}$ between 90 and 98, and is greater than Millstone Hill by $\sim 5 \mathrm{~m} / \mathrm{s}$ between 100 and $105 \mathrm{~km}$ and that the phases are similar throughout this height range. The TIDI semidiurnal amplitude at $105^{\circ} \mathrm{W}$ is close to the Millstone Hill profile throughout the height range. The phase offset from the Millstone Hill profile is less than $2 \mathrm{~h}$.

[22] As with the other comparisons presented in the paper, the agreement between the different sets of observations is striking. The TIDI diurnal amplitudes for Fort Collins and Plattville (described above) are close to the lidar and MF radar at $80 \mathrm{~km}$. The agreement with the lidar remains good throughout the rest of the profile (the variability in the lidar 

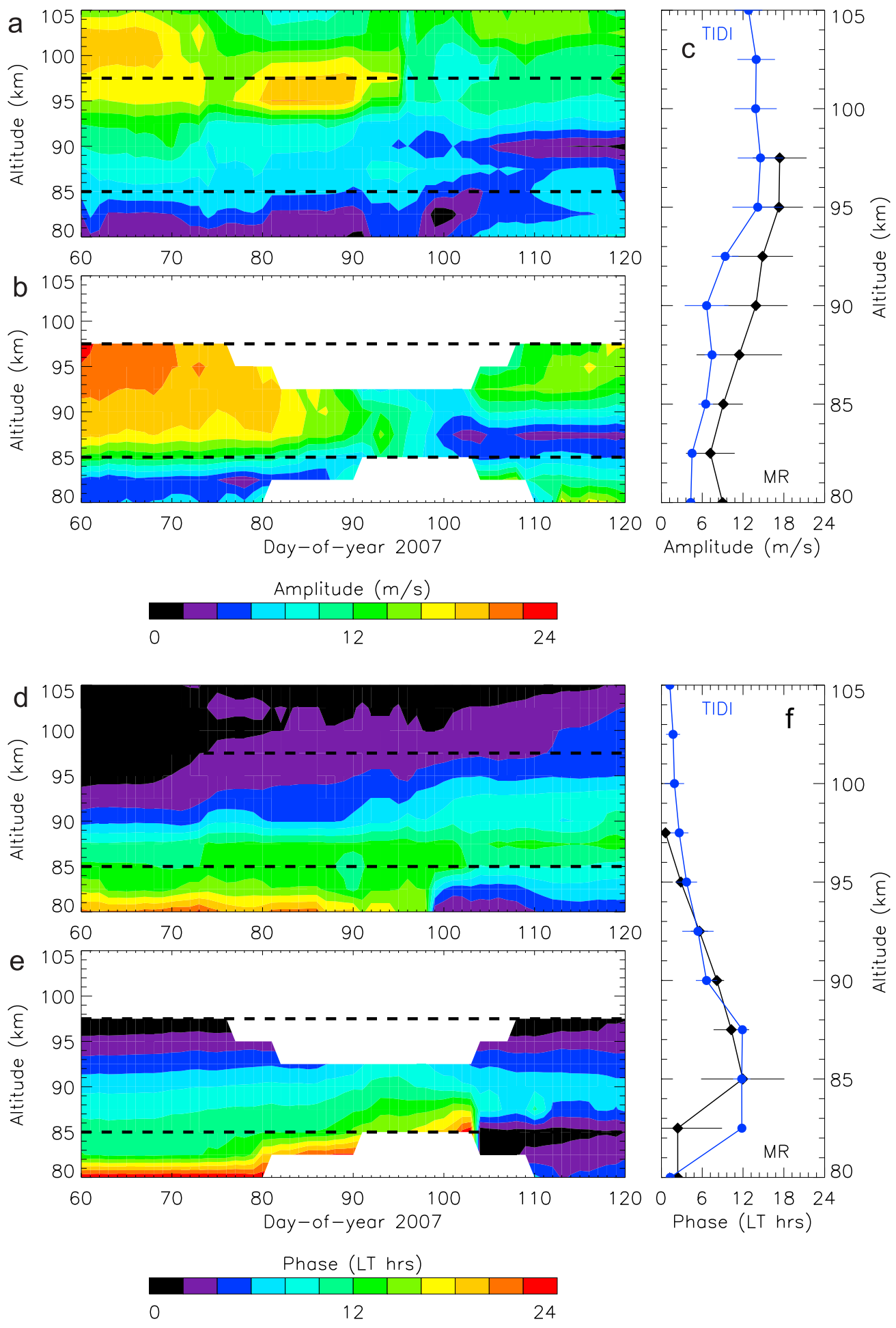

Figure 3. Time series of the (a and b) amplitude and ( $d$ and e) phase (local solar time of maximum) of the zonal diurnal tide (60 day running means) during March-April 2007 (second campaign) as derived from TIDI observations (Figures $3 \mathrm{a}$ and $3 \mathrm{~d}$ ) and meteor radar at Kototobang (Figures 3b and $3 \mathrm{e}$ ). (c and f) Campaign means for the observation sets (horizontal bars are standard deviation).

profile is thought to be due to the shorter data set) but the MF radar amplitude profile is less than the others. The lidar diurnal amplitudes show more variability as expected and the amplitudes lie between the TIDI and MF radar results.
At $100 \mathrm{~km}$ where the ISR radar results start, there is good agreement between the lidar, and the ISR observations and the TIDI results. The ISR results remain in good agreement for this component up to $105 \mathrm{~km}$. The model results in this 

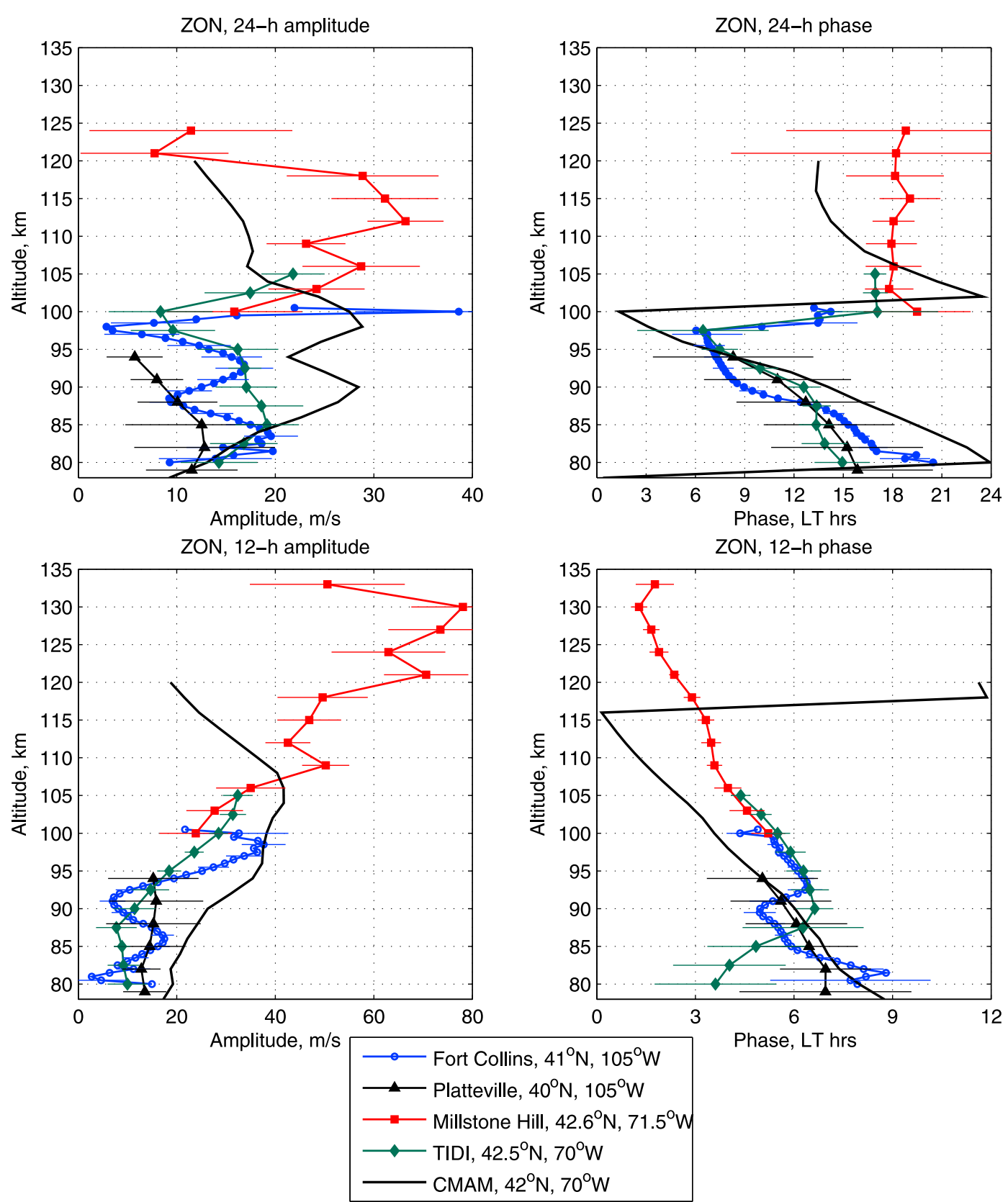

Figure 4. Height profiles (first campaign, September-October, 2005) of the (left) amplitude and (right) phase (local solar time of maxim) of the (top) diurnal and (bottom) semidiurnal tide derived from the eCMAM, TIDI (derived for locations near Millstone Hill), lidar, MF radar, and IS radar. Horizontal bars indicate standard deviation.

case are of larger amplitude than the observations up to $\sim 105 \mathrm{~km}$ and then decrease below the observations.

[23] The phase observations for the diurnal component for all the observations and the model are in good agreement. The phases of the observations agree within the standard deviations. They decrease with height to $\sim 100 \mathrm{~km}$ where they become stationary with height. As with the amplitude, the ISR phase matches well with the TIDI phase. The model phase decreases with height more quickly than the observations and becomes stationary at $110 \mathrm{~km}$.

[24] The agreement for the semidiurnal results is also very good. All the amplitudes below $100 \mathrm{~km}$ cluster within $\pm 5 \mathrm{~m} / \mathrm{s}$ of each other and as with the diurnal component the lidar observations vary more with height. The ISR results match the TIDI results within $5 \mathrm{~m} / \mathrm{s}$ in the region of overlap and at $100 \mathrm{~km}$ match the lidar results within $5 \mathrm{~m} / \mathrm{s}$. As with the zonal component the model is larger than the observations up to $105 \mathrm{~km}$ and less above this height.

[25] Above $85 \mathrm{~km}$ the agreement in the phases is very good and within experimental error. Between 92 and $105 \mathrm{~km}$ the phases of all the observations other than the MF radar decrease with height and are close to coincident. Below $92 \mathrm{~km}$, the lidar and TIDI phases vary considerably with more temporal variability. The model phase and the MF 
radar phase are in good agreement and above $92 \mathrm{~km}$ the model has a shorter vertical wavelength, leading to about 1-3 h offset from measurements.

\section{Discussion and Conclusions}

[26] In this paper we have presented a number of comparisons between tidal wind amplitudes and phases from a model and a number of different instruments. These comparisons are a subset of the comparisons which have been undertaken as part of the CAWSES Global Tidal Campaign and are representative of the type of agreement which is being achieved. These comparisons were selected to demonstrate agreement over a significant latitude range, zonal and meridional tidal winds and diurnal and semidiurnal components and indicate the status of comparisons with models. The comparisons between the various types of observations are very good. The model results demonstrate that the basic form of the tidal signatures is the same as in the observations but the component mix is not correct.

[27] The agreement between satellite and ground-based instrumentation has been achieved by ensuring the observations were from the same time period and recognizing that suitable comparisons can best be achieved by superposing all the tidal components of the same period observed by the satellite to reconstruct the ground observations. These results suggest that the long-standing issue between radar (apart from the MF radar speed bias (low by more than $20 \%$ at 91-94 km [Hall et al., 2005]) and possible E region contamination at similar heights [Hocking, 1997]) and satellite wind observations which developed in the 1990s when tidal comparisons between the UARS wind instruments and ground-based radars were undertaken [Khattatov et al., 1996] is largely resolved. Optical observations from satellites and ground-based radars observe the same wind fields. The primary issue with earlier comparisons is that they did not include the nonmigrating components as part of the comparison.

[28] Achievement of this level of agreement between satellite and ground-based observations establishes the observational foundations from which further work can proceed. Past differences between satellite and groundbased observations led to doubts in the observation techniques involved. Work can now proceed more coherently, with satellite and ground-based observations providing complementary data sets with which models can be validated and on which mesospheric assimilation efforts can be based.

[29] Comparisons between observations and results from a general circulation model, the eCMAM, were presented. The reconstructed fields from TIDI and the eCMAM both showed the significant geographical variability inherent in the tidal fields as a result of the superposition of the various tidal components. These superposition plots are an extremely sensitive means of evaluating how well a model simulates the tidal fields. Agreement with observations requires the correct simulation of the amplitudes and phases of all the components in the model.

[30] The agreement between the model and observations was reasonable and indicates that, while the model provides useful insights into the nature of the tidal signatures in the atmosphere, significant work is still required before the modeled tidal signatures can match observations. This will involve the examination of the nature of the model tidal forcing (both direct and parameterized) as well as the interactions between the tides, zonal means and other waves.

[31] In this paper, wind measurements have been emphasized. Similar comparisons for other parameters directly associated with tidal dynamics such as temperature and those with dependencies on tidal variables such as airglow, constituent distributions, sporadic E, magnetic fields, etc., are under way as part of the CAWSES Tidal Campaign effort. In addition, collection of data which will provide information on the tidal forcing during these periods is also being undertaken. Confirming that the behavior of these parameters is consistent with the physical description of their tidal dependencies and demonstrating that the observed tides can be directly linked to the observed forcing are important scientific challenges which remain to be solved. It appears that tidal modulation of constituent and dynamical phenomena in the mesosphere and lower thermosphere is a major driver at these heights and one that is only starting to be investigated in detail.

[32] Acknowledgments. William Ward, Ding Yi Wang, and Jian Du were supported by the National Science and Engineering Research Council, the Canadian Space Agency, and the Canadian Foundation for Climate and Atmospheric Science. Jens Oberheide was supported by the DFG through its CAWSES priority program, grant OB 299-2/2. L. Goncharenko was supported by NSF cooperative agreement ATM 0417666. The Millstone Hill incoherent scatter radar is supported by the U.S. National Science Foundation (NSF) as part of the Upper Atmosphere Facility Program. The Cachoeira Paulista meteor radar is operated by the Instituto Nacional de Pesquisas Espaciais, Brazil. The work at Colorado State University is supported by NSF under grant ATM-0545221. The Kototabang meteor radar was supported by the Japanese Ministry of Education, Culture, Sports, Science and Technology (MEXT) (grants 13136203 and 19403009). Werner Singer and Peter Hoffmann were supported by the DFG through its CAWSES priority program, grants SI 501/5-1 and SI 501/5-2.

\section{References}

Chapman, S., and R. S. Lindzen (1970), Atmospheric Tides, Reidel, Dordrecht, Netherlands.

Cierpik, K. M., J. M. Forbes, S. Miyahara, Y. Miyoshi, A. Fahrutdinova, C. Jacobi, A. Manson, C. Meek, N. J. Mitchell, and Y. Portnyagin (2003), Longitude variability of the solar semidiurnal tide in the lower thermosphere through assimilation of ground- and space-based wind measurements, J. Geophys. Res., 108(A5), 1202, doi:10.1029/ 2002JA009349.

Du, J., W. E. Ward, J. Oberheide, T. Nakamura, and T. Tsuda (2007), Semidiurnal tides from the Extended Canadian Middle Atmosphere Model (CMAM) and comparisons with TIMED Doppler Interferometer (TIDI) and meteor radar observations, J. Atmos. Sol. Terr. Phys., 69, 2159 2202, doi:10.1016/j.jastp.2007.07.014.

Fomichev, V. I., W. E. Ward, S. R. Beagley, C. McLandress, J. C. McConnell, N. A. McFarlane, and T. G. Shepherd (2002), Extended Canadian Middle Atmosphere Model: Zonal-mean climatology and physical parameterizations, J. Geophys. Res., 107(D10), 4087, doi:10.1029/2001JD000479.

Forbes, J. M. (1995), Tidal and planetary waves, in The Upper Mesosphere and Lower Thermosphere: A Review of Experiment and Theory, Geophys. Monogr. Ser, vol. 87, edited by R. M. Johnson and T. L. Killeen, pp. $67-$ 87, AGU, Washington, D. C

Forbes, J. M., and D. Wu (2006), Solar tides as revealed by measurements of mesosphere temperature by the MLS experiment on UARS, J. Atmos. Sci., 63, 1776-1797, doi:10.1175/JAS3724.1.

Forbes, J. M., X. Zhang, E. Talaat, and W. E. Ward (2003), Nonmigrating diurnal tides in the thermosphere, J. Geophys. Res., 108(A1), 1033, doi:10.1029/2002JA009262.

Forbes, J. M., X. Zhang, S. Palo, J. Russell, C. J. Mertens, and M. Mlynczak (2008), Tidal variability in the ionospheric dynamo region, J. Geophys. Res., 113, A02310, doi:10.1029/2007JA012737.

Fukao, S. (2007), Recent advances in atmospheric radar study, J. Meteorol. Soc. Jpn., 85B, 215-239, doi:10.2151/jmsj.85B.215.

Grieger, N., E. M. Volodin, G. Schmitz, P. Hoffmann, A. H. Manson, D. C. Fritts, K. Igarashi, and W. Singer (2002), General circulation model results 
on migrating and nonmigrating tides in the mesosphere and lower thermosphere. Part I: comparison with observations, J. Atmos. Sol. Terr. Phys., 64, 897-911, doi:10.1016/S1364-6826(02)00045-7.

Hagan, M. E., and J. M. Forbes (2002), Migrating and nonmigrating diurnal tides in the middle and upper atmosphere excited by tropospheric laten heat release, J. Geophys. Res., 107(D24), 4754, doi:10.1029/ 2001JD001236.

Hall, C. M., T. Aso, M. Tsutsumi, S. Nozawa, A. H. Manson, and C. E. Meek (2005), A comparison of mesosphere and lower thermosphere neutral winds as determined by meteor and medium-frequency radar at $70^{\circ} \mathrm{N}$ Radio Sci., 40, RS4001, doi:10.1029/2004RS003102.

Hocking, W. K. (1997), Strengths and limitations of MST radar measurements of middle-atmosphere winds, Ann. Geophys., 15, 1111-1122, doi:10.1007/s00585-997-1111-1.

Jackson, D. R. (1994), Tides in the Extended UGAMP General Circulation Model, Q. J. R. Meteorol. Soc., 120, 1589-1611, doi:10.1002/ qj. 49712052008 .

Khattatov, B. V., et al. (1996), Dynamics of the mesosphere and lower thermosphere as seen by MF radars and by the high-resolution Doppler imager/UARS, J. Geophys. Res., 101, 10,393-10,404, doi:10.1029/ 95JD01704.

Killeen, T. L., Q. Wu, S. C. Solomon, D. A. Ortland, W. R. Skinner, and R. J. Niciejewski (2006), TIMED Doppler Interferometer: Overview and recent results, J. Geophys. Res., 111, A10S01, doi:10.1029/ 2005JA011484

Lieberman, R., and C. B. Leovy (1995), Model of nonmigrating diurnal tides between the surface and $65 \mathrm{~km}$, J. Atmos. Sci., 52, 389-409, doi:10.1175/1520-0469(1995)052<0389:ANMOND>2.0.CO;2.

Manson, A. H., Y. Luo, and C. Meek (2002), Global distributions of diurnal and semi-diurnal tides: Observations from HRDI-UARS of the MLT region, Ann. Geophys., 20, 1877-1890.

Manson, A. H., et al. (2004a), Longitudinal and latitudinal variations in dynamic characteristics of the MLT (70-95 km): A study involving the CUJO network, Ann. Geophys., 22, 347-365.

Manson, A. H., C. E. Meek, M. Hagan, X. Zhang, and Y. Luo (2004b), Global distributions of diurnal and semi-diurnal tides: Observations from HRDI-UARS of the MLT region and comparisons with GSWM-02 (migrating, non-migrating components), Ann. Geophys., 22, 1529-1548.

Manson, A. H., et al. (2009), Arctic tidal characteristics at Eureka $\left(80^{\circ} \mathrm{N}\right.$, $\left.86^{\circ} \mathrm{W}\right)$ and Svalbard $\left(78^{\circ} \mathrm{N}, 16^{\circ} \mathrm{E}\right)$ for $2006 / 7$ : Seasonal and longitudina variations, migrating and non-migrating tides, Ann. Geophys., 27, 11531173.

McLandress, C. (1997), Seasonal variability of the diurnal tide: Results from the Canadian middle atmosphere general circulation model, J. Geophys. Res., 102, 29,747-29,764, doi:10.1029/97JD02645.

Miyahara, S., and Y. Miyoshi (1997), Migrating and non-migrating atmospheric tides simulated by a middle atmosphere general circulation model, Adv. Space Res., 20, 1201-1207, doi:10.1016/S0273-1177(97)00773-4.

Miyahara, S., Y. Miyoshi, and K. Yamashita (1999), Variations of migrating and nonmigrating tides simulated by the middle atmosphere circulation model at Kyushu University, Adv. Space Res., 24, 15491558, doi:10.1016/S0273-1177(99)00879-0.

Mlynczak, M. G., B. T. Marshall, F. J. Martin-Torres, J. M. Russell III, R. E. Thompson, E. E. Remsberg, and L. L. Gordley (2007), Sounding of the Atmosphere using Broadband Emission Radiometry observations of daytime mesospheric $\mathrm{O}_{2}\left({ }^{1} \Delta\right) 1.27 \mu \mathrm{m}$ emission and derivation of ozone, atomic oxygen, and solar and chemical energy deposition rates, J. Geophys. Res., 112, D15306, doi:10.1029/2006JD008355.

Murphy, D. J., et al. (2006), A climatology of tides in the Antarctic mesosphere and lower thermosphere, J. Geophys. Res., 111, D23104, doi:10.1029/2005JD006803.
Oberheide, J., and J. M. Forbes (2008), Tidal propagation of deep tropical cloud signatures into the thermosphere from TIMED observations, Geophys. Res. Lett., 35, L04816, doi:10.1029/2007GL032397.

Oberheide, J., Q. Wu, T. L. Killeen, M. E. Hagan, and R. G. Roble (2006), Diurnal nonmigrating tides from TIMED Doppler Interferometer wind data: Monthly climatologies and seasonal variations, J. Geophys. Res., 111. A10S03 doi:10.1029/2005JA011491.

Oberheide, J., Q. Wu, T. L. Killeen, M. E. Hagan, and R. G. Roble (2007), A climatology of nonmigrating semidiurnal tides from TIMED Doppler Interferometer (TIDI) wind data, J. Atmos. Sol. Terr. Phys., 69, 22032218, doi:10.1016/j.jastp.2007.05.010.

Pancheva, D., et al. (2002), Global scale tidal structure in the mesosphere and lower thermosphere during the PSMOS campaign of June-August 1999 and comparisons with the global scale wave model, J. Atmos. Sol. Terr. Phys., 64, 1011-1035, doi:10.1016/S1364-6826(02)00054-8.

She, C.-Y., et al. (2003), The first 80-hour continuous lidar campaign for simultaneous observation of mesopause region temperature and wind, Geophys. Res. Lett., 30(6), 1319, doi:10.1029/2002GL016412.

Talaat, E. R., and R. S. Lieberman (1999), Nonmigrating diurnal tides in mesospheric and lower thermospheric winds and temperatures, J. Atmos. Sci., 56, 4073-4087, doi:10.1175/1520-0469(1999)056<4073:NDTIMA>2.0. $\mathrm{CO} ; 2$

Ward, W. E., V. I. Fomichev, and S. Beagley (2005), Nonmigrating tides in equinox temperature fields from the Extended Canadian Middle Atmosphere Model (CMAM), Geophys. Res. Lett., 32, L03803, doi:10.1029/ 2004 GL021466.

Yuan, T., H. Schmidt, C. Y. She, D. A. Krueger, and S. Reising (2008), Seasonal variations of semidiurnal tidal perturbations in mesopause region temperature and zonal and meridional winds above Fort Collins, Colorado $\left(40.6^{\circ} \mathrm{N}, 105.1^{\circ} \mathrm{W}\right), J$. Geophys. Res., 113, D20103, doi:10.1029/ 2007JD009687.

Zwiers, F., and K. Hamilton (1986), Simulations of solar tides in the Canadian Climate Centre general circulation model, J. Geophys. Res., 91, 11,87711,896, doi:10.1029/JD091iD11p11877.

P. Batista and B. Clemesha, National Space Research Institute, CP 515, 12227-010, Saõ José dos Campos, SP, Brazil

L. C. Chang, Department of Aerospace Engineering Sciences, University of Colorado at Boulder, 429 UCB, Boulder, CO 80309-0429, USA.

J. Du, Department of Applied Mathematics and Theoretical Physics, Cambridge University, Wilberforce Road, Cambridge CB3 0WA, UK.

L. P. Goncharenko, Haystack Observatory, MIT, Westford, MA 01886 , USA.

P. Hoffmann and W. Singer, Leibniz Institute of Atmospheric Physics, University of Rostock, Schlossstr. 6, D-18225 Kühlungsborn, Germany.

A. H. Manson, Institute of Space and Atmospheric Studies, University of Saskatchewan, 116 Science Pl., Saskatoon, SK S7N 5E2, Canada.

T. Nakamura, National Institute of Polar Research, 10-3 Midoricho, Tachikawa, 190-8518 Tokyo, Japan.

J. Oberheide, Department of Physics, University of Wuppertal, Gauss Str. 20, D-42097 Wuppertal, Germany.

D. M. Riggin, Colorado Research Associates, 3380 Mitchell Ln., Boulder, CO 80301, USA.

C.-Y. She and T. Yuan, Department of Physics, Colorado State University, Fort Collins, CO 80523-1875, USA.

T. Tsuda, RISH, Kyoto University, Uji, Kyoto 611-0011, Japan.

D.-Y. Wang and W. E. Ward, Department of Physics, University of New Brunswick, PO Box 4400, Fredericton, NB E3B 5A3, Canada. (wward@ unb.ca) 